\title{
Mercado de Produtos Florestais no Estado do Rio de Janeiro
}

\author{
Wilson Ferreira de Mendonça Filho \\ Instituto de Florestas - IF, Universidade Federal Rural do Rio de Janeiro - UFRRJ
}

\begin{abstract}
RESUMO
Desde a época do pau-brasil, as florestas fluminenses têm fornecido produtos para o desenvolvimento estadual, como toras, lenha e carvão. Para avaliar a oferta e a demanda destes produtos, foram analisados dados do IBGE gerados a partir do levantamento da Produção Vegetal e da Silvicultura (PEVS) e informações coletadas pelo IBAMA através dos documentos de origem florestal (DOF). No Estado do Rio de Janeiro, a produção de produtos florestais não madeireiros é pouquíssimo expressiva. Já a de produtos florestais madeireiros tem uma expressiva demanda desde lenha e carvão vegetal até madeira serrada, passando por madeira para papel e celulose e também para o grupo outras finalidades.
\end{abstract}

Palavras-chave: produtos florestais, oferta, demanda.

\section{Forest Products Market of Rio de Janeiro State}

\begin{abstract}
Since the Brazilian-wood age the forests in the State of Rio de Janeiro are supplying products to the region development as round-wood, firewood and charcoal. The supply and demand evaluation of these products was analyzed using the IBGE data on the Silviculture and Vegetal Production survey (PEVS) and the IBAMA data on the Forest Origin Document survey (DOF). The non-wood forestry production is not quite expressive. However, wood products have a very expressive demand for firewood and charcoal through sawn-wood, passing by pulp and paper wood and also to the other group finalities.
\end{abstract}

Keywords: forest products, supply, demand. 


\section{INTRODUÇÃO}

O Estado do Rio de Janeiro tem sido historicamente um grande consumidor de produtos florestais. Desde a época da exploração intensiva do pau-brasil, nossas matas têm fornecido produtos florestais no processo de desenvolvimento econômico e social do Estado. Estes produtos florestais, classificados em diversas formas, foram consumidos pela população durante todo o período de implantação da sociedade fluminense. Durante este processo, alguns destes produtos florestais foram extremamente explorados, como a madeira das matas, utilizada como toras, lenha e carvão, causando a expressiva redução da cobertura florestal original. Afortunadamente, o cenário mudou, pois, através da conscientização e da legislação ambiental, está sendo possível a preservação do restante da mata atlântica do Estado apesar da pressão, ainda existente, sobre os recursos florestais. Esta pressão sobre os produtos florestais é exercida em vários níveis da sociedade, seja pelo consumo do palmito, seja pelo consumo da lenha para uso doméstico, ou da madeira para construções, sem falar nos problemas da expansão urbana que acelera a demanda por estes produtos e tende a reduzir as áreas cobertas com vegetação nativa.

O comércio destes produtos vem se modificando durante os anos, variando de acordo com a procura desses bens pela sociedade e de acordo com as mudanças econômicas e culturais pelas quais tem passado o País e, particularmente, o Estado do Rio de Janeiro.

Apesar de o termo produtos florestais ser plenamente conhecido, por todos aqueles ligados às ciências florestais, são tantos os diferentes tipos dos chamados produtos florestais que merecem uma classificação mais detalhada, visando um melhor entendimento. Como partida, tem-se a separação destes produtos em duas classes distintas: os produtos florestais madeireiros e os produtos florestais não madeireiros. Os primeiros são dos tipos mais conhecidos, como a madeira em toras que tem sua utilização na indústria da construção civil, na indústria moveleira e também na forma de lenha ou carvão para uso doméstico ou industrial. Os produtos florestais não madeireiros englobam produtos utilizados pelas indústrias químicas $\mathrm{e}$ farmacêuticas, como resinas, borrachas, gomas não elásticas, tanantes, aromáticos entre outros. $\mathrm{O}$ Instituto Brasileiro de Geografia e Estatística (IBGE) classifica estes produtos dentro de dois grandes grupos distintos: aqueles provenientes das atividades da extração em matas nativas (Produtos da Extração Vegetal) e aqueles oriundos dos reflorestamentos (Produtos da Silvicultura) Tabela 1.

Já o Instituto Brasileiro de Meio Ambiente (IBAMA) tem outra classificação para produtos florestais conforme descrito a seguir:

I) Produto florestal: aquele que se encontra em seu Estado bruto ou in natura: madeira em toras, toretes, postes não imunizados, escoramentos, palanques roliços, dormentes nas fases de extração/fornecimento, estacas e moirões, achas

Tabela 1. Classificação do IBGE para produtos florestais. Table 1. IBGE forestry products classification.

\section{Produtos da extração vegetal}

Grupo 1 - Borrachas

Caucho, Hévea, Mangabeira

Grupo 2 - Gomas năo elásticas

Balata, Maçaranduba, Sorva

Grupo 3 - Ceras

Carnaúba, Outras

Grupo 4 - Fibras (fibra bruta)

Buriti, Carnaúba, Piaçava, Outras

Grupo 5 - Tanantes

Angico, Barbatimão, Outras

Grupo 6 - Oleaginosos

Babaçu, Copaíba, Cumaru, Licuri, Oiticica, Pequi,

Tucum, Outras

Grupo 7 - Alimentícios

Açaí, Castanha de caju, Castanha-do-pará, Erva-mate, Mangaba, Palmito, Pinhão (fruto da araucária), Umbu

Grupo 8 - Aromáticos, medicinais, tóxicos e corantes Ipecacuanha ou poaia, Jaborandi, Urucum, Outras

Grupo 9 - Madeiras

Carvão vegetal, Lenha, Madeira em tora, Nó-de-pinho, Pinheiro brasileiro

\section{Produtos da Silvicultura}

- Carvão vegetal

- Cascas secas de acácia-negra

- Folhas de eucalipto

- Lenha

- Madeira em tora para papel e celulose

- Madeira em tora para outras finalidades

- Resinas

Fonte: IBGE (Instituto..., 2003). 
e lascas, pranchões desdobrados com motosserra, bloco ou filé (tora em formato poligonal, obtida a partir da retirada de costaneiras), lenha, palmito, xaxim, óleos essenciais; e

II) Subproduto florestal: aquele que passou por processo de beneficiamento na forma relacionada: madeira serrada sob qualquer forma, laminada e faqueada, resíduos da indústria madeireira (aparas, costaneiras, cavacos e demais restos de beneficiamento e de industrialização de madeira) quando destinados para fabricação de carvão, dormentes e postes na fase de saída da indústria, carvão de resíduos da indústria madeireira, carvão vegetal nativo empacotado, na fase posterior à exploração e produção, xaxim e seus artefatos na fase de saída da indústria.

O objetivo deste trabalho é analisar a oferta e a demanda de produtos florestais no Estado do Rio de Janeiro. Analisa-se também a distribuição e o valor da madeira serrada por municípios e regiões de governo e o valor deste produto

\section{PROCEDIMENTOS}

Devido à falta de dados e informações primárias sobre a oferta dos produtos florestais madeireiros e não madeireiros na forma de estoque, utilizam-se, para um melhor entendimento da situação, os dados secundários do Instituto Brasileiro de Geografia e Estatística (IBGE) através do levantamento das informações sobre a produção do setor extrativo vegetal e da silvicultura (PEVS) (Instituto..., 2003, 2006). A análise da Produção de Extração Vegetal e da Silvicultura tem por finalidade gerar informações sobre a quantidade e o valor das produções obtidas mediante o processo de exploração dos recursos florestais naturais, denominado extrativismo vegetal, bem como da exploração de maciços florestais plantados (silvicultura).

Também foram utilizados os dados do Instituto Brasileiro do Meio Ambiente e dos Recursos Naturais Renováveis (IBAMA) referentes à movimentação de madeira dentro e fora dos Estados, denominados de Documento de Origem Florestal (DOF) (IBAMA, 2006, 2007). Estes dados contemplam somente a movimentação de produtos e subprodutos florestais oriundos de matas nativas. O Sistema DOF foi instituído pela Portaria/MMA/ $\mathrm{n}^{\circ} .253$, de 18 de agosto de 2006 e constitui-se numa licença obrigatória para o controle do transporte e armazenamento de produtos e subprodutos florestais de origem nativa, inclusive o carvão vegetal nativo, contendo as informações sobre a comercialização desses produtos e subprodutos. Infelizmente, estes dados não discriminam as espécies constantes nos relatórios divulgados.

Estes instrumentos consistem, atualmente, na única fonte oficial de informações sobre a produção e a movimentação de produtos florestais no Estado do Rio de Janeiro.

\section{RESULTADOS}

Neste trabalho, considera-se como oferta a produção de produtos florestais conforme identificada nos levantamentos realizados pelo Instituto Brasileiro de Geografia e Estatística (IBGE) e como demanda o consumo de produtos florestais conforme identificado nos dados obtidos no sistema DOF, realizado pelo Instituto Brasileiro de Meio Ambiente e dos Recursos Naturais Renováveis (IBAMA).

A oferta de produtos florestais não madeireiros é pouco expressiva no Estado do Rio de Janeiro. De acordo com a pesquisa do IBGE, no tema Extração vegetal e Silvicultura, somente estiveram presentes o caju, do grupo "Alimentícios", e algumas fibras vegetais, classificadas no grupo denominado como "Outras".

A oferta dos produtos florestais madeireiros, no Estado do Rio de Janeiro, está representada pelos produtos do grupo Extração Vegetal e pelo grupo dos produtos da Silvicultura. Em relação ao primeiro grupo, a oferta está praticamente restrita aos remanescentes da mata nativa, no Estado, mesmo que usados de forma ilegal.

A oferta de produtos florestais madeireiros provenientes de reflorestamentos dentro do Estado é, a cada dia, mais expressiva, mostrando, do ano de 2002 para 2006, um crescimento médio de $68 \%$ na produção de carvão, lenha, e toras para papel e celulose e para outros fins.

\subsection{Oferta de Produtos da extração vegetal}

\subsubsection{Produtos não madeireiros}

- Castanha de Caju - classificada no grupo "Alimentícios", tem tido uma produção constante, 
mostrando um acréscimo de cerca de $20 \%$, passando de $5 \mathrm{t}$ em 2002 para uma produção de $6 \mathrm{t}$ ao ano em 2006.

- Outras fibras - no grupo fibras, classificadas como outras fibras, estão vários tipos de fibras de diferentes espécies, que tiveram uma redução de $14 \%$ na produção, quando observado o período de 2002 a 2006, caindo de 7 para 6 t/ano.

- Carvão vegetal - analisando as informações referentes à produção de carvão vegetal, é possível verificar que a oferta que era de $30 \mathrm{t}$ no ano de 2002, apresentou um declínio de mais de $70 \%$ no ano de 2003. Nos anos seguintes, quase retornou ao patamar de 2002, chegando a $25 \mathrm{t}$ nos anos de 2004 e 2005 e mostrou uma elevação expressiva de cerca de $80 \%$ em 2006, alcançando 124 t (Figura 1).

- Lenha - a produção de lenha mostra um pequeno declínio de 2002 a 2004, passando de $38.194 \mathrm{~m}^{3}$, para $36.047 \mathrm{~m}^{3}$. No ano seguinte, ocorre uma pequena redução de $5 \%$, passando para $34,135 \mathrm{~m}^{3}$, que se mantém estável no ano de 2005. No ano de 2006, há uma elevação de mais de 57\%, alcançando uma produção de $53.441 \mathrm{~m}^{3}$ (Figura 2).

- Madeira em toras - a produção de madeira em toras vem decaindo desde 2002, mostrando uma redução drástica, de mais de $97 \%$ para

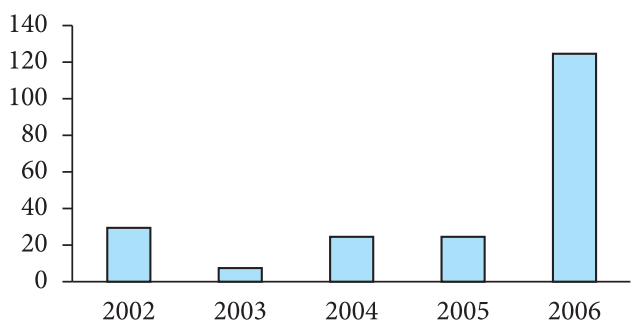

Figura 1. Produção de carvão vegetal de mata nativa, em toneladas de 2002 a 2006, no Estado do Rio de Janeiro (IBGE/PEVS).

Figure 1. Native charcoal production in tons from 2002 to 2006, in the Rio de Janeiro State (IBGE/PEVS).

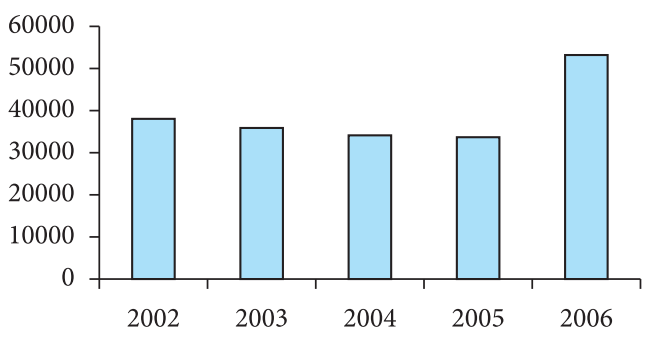

Figura 2. Produção de lenha de mata nativa, em $\mathrm{m}^{3} \mathrm{de}$ 2002 a 2006 no Estado do Rio de Janeiro (Fonte: IBGE/ PEVS).

Figure 2. Native firewood production, in cubic meters from 2002 to 2006 in Rio de Janeiro State (IBGE/PEVS).
2003, que passou de $39.917 \mathrm{~m}^{3}$ para $1.121 \mathrm{~m}^{3}$, se manteve estável durante os anos de 2004 e 2005 e apresentou uma pequena elevação de $8,6 \%$ em 2006, apresentando uma produção de $1.193 \mathrm{~m}^{3}$ (Figura 3).

\subsubsection{Oferta de produtos da silvicultura}

- Carvão - a produção de carvão vegetal proveniente de reflorestamentos teve um crescimento de mais de $55 \%$ de 2002 a 2003 , passando de 802 t para $1.245 \mathrm{t}$, de $59 \%$ em 2004 com $1980 \mathrm{t}$ e para mais de $160 \%$ para o ano de 2005, alcançando 5.294 t. No ano de 2006, há um pequeno declínio, ficando a produção do ano na marca de $5.186 \mathrm{t}$, mostrando uma redução de $2 \%$ (Figura 4).

- Lenha - a produção de lenha proveniente de reflorestamentos teve um decréscimo de cerca de $10 \%$ de 2002 a 2003 , passando de $307.873 \mathrm{~m}^{3}$ para $278.474 \mathrm{~m}^{3}$ e um pequeno acréscimo de $0,3 \%$ na produção de 2004, ficando com $287.221 \mathrm{~m}^{3}$. Em 2005 mostrou um crescimento de mais de 13\%, com $331.997 \mathrm{~m}^{3}$, continuando a crescer em 2006 com 18\%. O ano de 2006 fechou com produção de $393.707 \mathrm{~m}^{3}$ (Figura 5).

- Papel e Celulose - a produção de madeira em

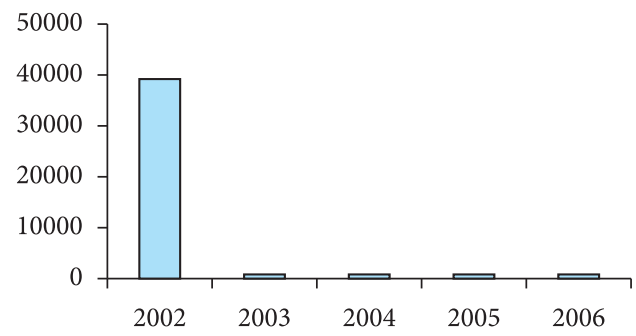

Figura 3. Produção de madeira em toras de mata nativa, em m³ ${ }^{3}$, de 2002 - 2006 no Estado do Rio de Janeiro (IBGE/PEVS).

Figure 3. Native round wood production, in cubic meters from 2002 to 2006 in Rio de Janeiro State (IBGE/PEVS).

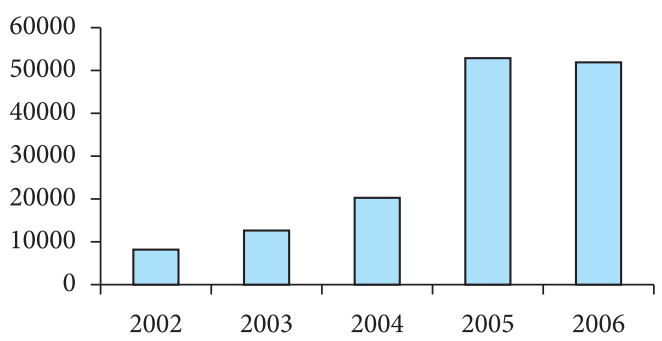

Figura 4. Produção de carvão vegetal de reflorestamentos, em toneladas, de 2002 a 2006 no Estado do Rio de Janeiro (Fonte: IBGE).

Figure 4. Planted forest charcoal production, in tons, from 2002 to 2006 in Rio de Janeiro State (IBGE). 
toras para papel e celulose não apresentou registro de produção para os anos de 2002 e 2003. No ano de 2004, foi registrado o valor de $11.296 \mathrm{~m}^{3}$ produzidos. Há uma elevação expressiva de 2004 para 2005, passando para $102.448 \mathrm{~m}^{3}$, mostrando uma elevação de mais de 8 vezes. Do ano de 2005 para 2006, há um pequeno acréscimo de $1,5 \%$, ficando a produção do ano na marca de $104.100 \mathrm{~m}^{3}$ (Figura 6)

- Outras finalidades - a produção de madeira para o grupo outras finalidades, proveniente de reflorestamentos, teve um crescimento de mais de $45 \%$ de 2002 a 2003, passando de $18.741 \mathrm{~m}^{3}$, para $27.167 \mathrm{~m}^{3}$. Houve uma pequena variação de $7 \%$, passando para $29.626 \mathrm{~m}^{3} \mathrm{em} \mathrm{2004}$. Para o ano 2005, há uma elevação muitíssimo expressiva de aproximadamente $270 \%$, empurrando a produção para 79.979. No ano de 2006, há um pequeno acréscimo, ficando a produção do ano na marca de $81.855 \mathrm{~m}^{3}$, mostrando uma elevação de 2,3\% (Figura 7)

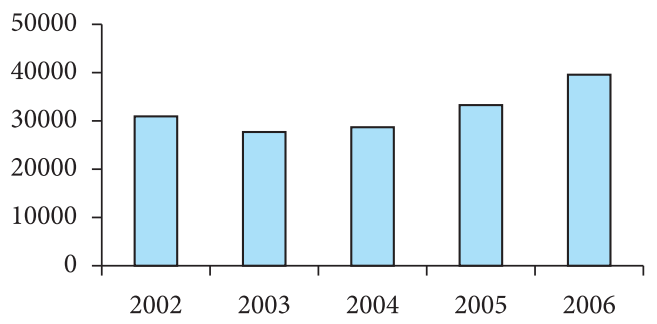

Figura 5. Produção de lenha de reflorestamentos, em $\mathrm{m}^{3}$, de 2002 a 2006, no Estado do Rio de Janeiro (Fonte: IBGE).

Figure 5. Planted forest firewood production, in cubic meters, from 2002 to 2006 in Rio de Janeiro State. (IBGE).

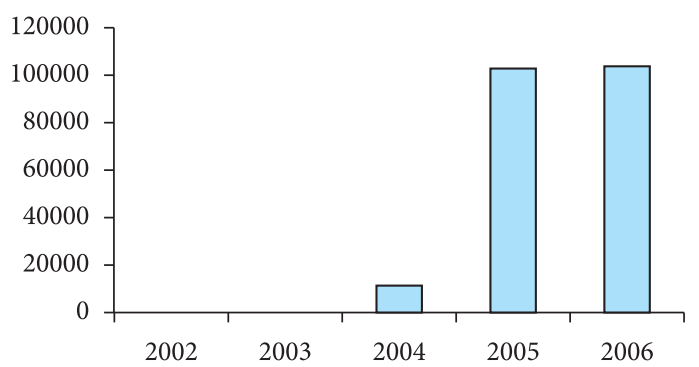

Figura 6. Produção de madeira em toras para papel e celulose, em m³ , de 2002 a 2006, no Estado do Rio de Janeiro (Fonte: IBGE).

Figure 6. Planted forest round wood production, in cubic meters, from 2002 to 2006 in Rio de Janeiro State (IBGE).

\subsubsection{Demanda de produtos madeireiros}

A comercialização e a movimentação de produtos madeireiros foram avaliadas através da análise das informações constantes nos relatórios do IBAMA referente aos DOF, conforme citado anteriormente. Estas informações referem-se ao período de setembro do ano de 2006 , quando o serviço começou a ser efetuado,até dezembro do ano de 2007.

- Lenha - no ano de 2006, de setembro a dezembro, e no ano de 2007, não foi registrado nenhum movimento de cargas de lenha originadas em municípios do Rio de Janeiro. No ano de 2006, de setembro a dezembro, e no ano de 2007 , não foi registrado nenhum movimento de cargas de lenha com destino a municípios do Rio de Janeiro.

- Carvão - nos anos de 2006 (de setembro a dezembro) e 2007, não foi registrado nenhum movimento de carga de carvão vegetal originado no Estado do Rio de Janeiro. Entretanto, houve uma movimentação de mais de $160.000 \mathrm{~m}$ de carvão de setembro de 2006 a dezembro de 2007, proveniente dos Estados do Paraná e Mato Grosso do Sul. Os municípios recebedores deste subproduto foram Barra Mansa, São João de Meriti e Saquarema. O maior volume (155.691 mdc) foi transportado do Mato Grosso do Sul para Barra Mansa e o restante foi enviado do Paraná para o município de São João de Meriti (7.442,39 mdc) e para o município de Saquarema (100 mdc).

- Madeira em toras - a movimentação de toras no período de setembro de 2006 a dezembro de 2007 foi de cerca de $500 \mathrm{~m}^{3}$. A maior parte deste volume, $96 \%$, foi originada fora do Estado do Rio de Janeiro, e o restante teve sua origem no próprio Estado. A madeira em toras de origem interna é

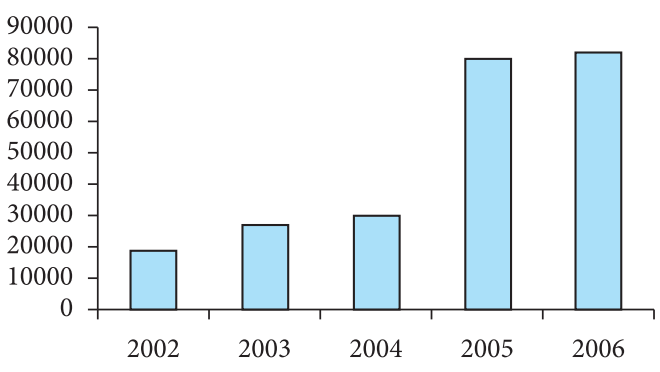

Figura 7. Madeira em toras para outras finalidades em $\mathrm{m}^{3}$, de 2002 a 2006, no Estado do Rio de Janeiro (Fonte: IBGE).

Figure 7. Planted round wood production to other uses, in cubic meters, from 2002 to 2006 in Rio de Janeiro State (IBGE). 
proveniente do município de Duque de Caxias, com $21,16 \mathrm{~m}^{3}$, e teve como destino o município do Rio de Janeiro. A madeira em toras originada fora do Estado foi distribuída entre os municípios de Silva Jardim, que recebeu $214 \mathrm{~m}^{3}$; Itaperuna, que recebeu $132 \mathrm{~m}^{3}$, Cabo Frio, com $61 \mathrm{~m}^{3}$; São João de Meriti, com $24 \mathrm{~m}^{3}$; Rio Bonito recebeu $12 \mathrm{~m}^{3}$; Armação dos Búzios, que recebeu $12 \mathrm{~m}^{3}$; e Laje do Muriaé, que também recebeu $12 \mathrm{~m}^{3}$. Todo este volume de madeira em toras, totalizando $479 \mathrm{~m}^{3}$, teve sua origem no Estado do Piauí no município de Várzea Branca, que serviu Itaperuna, Cabo Frio, Armação dos Búzios e Silva Jardim; no município de Santa Luz, que enviou para os municípios de São João de Meriti e Itaperuna; e no município de Tamboril do Piauí, que enviou madeira em toras para o município de Rio Bonito.

- Madeira serrada:

a) Origem em outro Estado - a movimentação de madeira serrada originada em outros Estados mostrou um volume de mais de $370.000 \mathrm{~m}^{3}$ no período de setembro de 2006 a dezembro de 2007, correspondendo a uma movimentação de quase 130 milhões de reais. Neste período, o preço médio pago pelo metro cúbico de madeira serrada foi de $\mathrm{R} \$ 348,33$ (Tabela 2).

A maior parte deste volume foi proveniente dos Estados do Pará, Rondônia e Mato Grosso, que totalizaram $94 \%$ do total do volume que ingressou no Estado. O restante do volume foi originado nos Estados do Acre, Amazonas, Amapá, Bahia, Espírito Santo, Minas Gerais, Santa Catarina, São Paulo e Rio Grande do Sul. Também foi registrada neste período uma movimentação de $36.000 \mathrm{~m}^{3}$ de madeira serrada referente à distribuição deste produto dentro do próprio Estado. Neste período, o Estado do Pará foi

Tabela 2. Volume $\left(\mathrm{m}^{3}\right)$, valor $(\mathrm{R} \$)$ e preço médio $(\mathrm{R} \$)$ de madeira serrada, originada em outros Estados, nos anos de 2006 (parte) e 2007.

Table 2. Sawn-wood volume $\left(\mathrm{m}^{3}\right)$, value $(\mathrm{R} \$)$ and medium price $(\mathrm{R} \$)$, originated in other states, in the years of 2006 (part) and 2007.

\begin{tabular}{|ccrc} 
Ano & $\begin{array}{c}\text { Volume } \\
\left(\mathbf{m}^{\mathbf{3}} \mathbf{x} \mathbf{1 0 0 0}\right)\end{array}$ & $\begin{array}{c}\text { Valor } \\
(\mathbf{R} \mathbf{\$} \mathbf{~ 1 0 0 0})\end{array}$ & $\begin{array}{c}\text { Valor médio } \\
\mathbf{R} \mathbf{\$} \mathbf{m}^{\mathbf{3}}\end{array}$ \\
\hline 2006 & 49,557 & $14.028,597$ & 283,08 \\
\hline 2007 & 322,022 & $115.405,245$ & 358,38 \\
\hline Total & 371,579 & $129.433,842$ & 348,33 \\
\hline
\end{tabular}

Fonte: DOF/IBAMA. o que mais enviou madeira serrada para o Estado do Rio de Janeiro, superando $170.000 \mathrm{~m}^{3}$. O Estado de Rondonia é o segundo maior exportador de madeira serrada para o Estado do Rio de Janeiro, com $88.000 \mathrm{~m}^{3}$. O Estado do Mato Grosso aparece como o terceiro maior produtor de madeira serrada para o Rio de Janeiro, com aproximadamente $55.000 \mathrm{~m}^{3}$. O município do Rio de Janeiro aparece como o quarto maior fornecedor com $36.000 \mathrm{~m}^{3}$, conforme apresentado na Figura 8.

Quando é considerada a procedência da madeira em relação à região produtora, a região norte fluminense desponta como a grande fornecedora com quase $72 \%$, de toda a madeira serrada com destino ao Estado do Rio de Janeiro, correspondendo a mais de $260.000 \mathrm{~m}^{3}$. Em seguida, com 15\% aparece, a região Centro-Oeste, com $55.000 \mathrm{~m}^{3}$. A região Sudeste aparece com cerca de $10 \%$ do volume total recebido pelo Estado do Rio de Janeiro, representando $38.000 \mathrm{~m}^{3}$. As regiões Nordeste e Sul têm participação pouco expressiva com valores em torno de $2 \%$, totalizando menos de $13.000 \mathrm{~m}^{3}$. $\mathrm{Na}$ distribuição da madeira serrada que ingressou no Estado durante o período anteriormente mencionado, a Região Metropolitana foi a que teve o maior volume de madeira com 164.566,790 $\mathrm{m}^{3}$, representando $44,3 \%$ do volume total. A região das baixadas litorâneas teve o segundo maior volume, $67.238,350 \mathrm{~m}^{3}$, correspondendo a $18 \%$ do volume total. A região serrana teve o terceiro maior volume, com $40.863,086 \mathrm{~m}^{3}$, representando $11 \%$ do total do volume de madeira serrada que entrou no Estado. A região norte fluminense recebeu $9,5 \%$ do volume

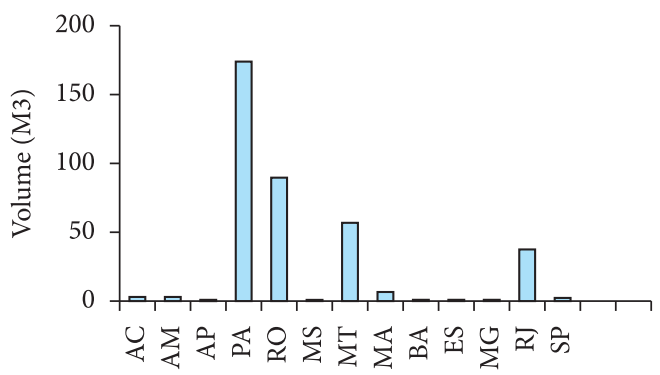

Figura 8. Volume $\left(\mathrm{m}^{3}\right)$ de madeira serrada por Estados fornecedores para o Rio de Janeiro no período de setembro de 2006 a dezembro de 2007 (DOF/IBAMA). Figure 8. Sawn-wood volume $\left(\mathrm{m}^{3}\right)$ by Rio de Janeiro State suppliers from September of 2006 to December of 2007 (DOF/IBAMA). 
total, perfazendo $35.290,847 \mathrm{~m}^{3}$. As regiões do Médio Paraíba e da Costa Verde receberam volumes de aproximadamente $6 \%$ do total, correspondendo a $23.031,921 \mathrm{~m}^{3}$ e $21.545,991 \mathrm{~m}^{3}$, respectivamente. As regiões norte fluminense e centro-sul fluminense registraram o recebimento de $2,5 \%$ do volume total, com 9.287,065 $\mathrm{m}^{3}$ cada. No período de setembro de 2006 a dezembro de 2007, o volume de madeira serrada que ingressou no Estado do Rio de Janeiro foi distribuído, em sua maior parte, para o município do Rio de Janeiro, com 22,8\% do total. Os municípios de Duque de Caxias (8,2\%), Petrópolis (5,4 \%) e Campos dos Goytacazes (5,3 \%) estão entre os que mais receberam madeira serrada. Os mais de $58 \%$ restantes do volume de madeira serrada, quantificando mais de $216.000 \mathrm{~m}^{3}$, estão distribuídos entre os outros 88 municípios, variando de $15.700 \mathrm{~m}^{3}$ $(4,2 \%)$ para o município de Nova Iguaçu, a apenas $5,1 \mathrm{~m}^{3}$, destinados ao município de São Jose de Ubá. Entre os municípios que detêm isoladamente menos de $1 \%$ do total, pode-se observar uma grande variação nos volumes recebidos que vão desde os 5 $\mathrm{m}^{3}$, referentes ao município de São José do Ubá, até $3.500 \mathrm{~m}^{3}$, recebidos pelo município de Itaboraí.

a) Origem no Estado do Rio de Janeiro - A madeira serrada com origem no Estado do Rio de Janeiro teve como destinatário os Estados do Amazonas, Minas Gerais, Pará, Paraná, Roraima, e São Paulo e o próprio Estado do Rio de Janeiro. Do total do volume originado no Estado, 96\%, representando mais de $36.000 \mathrm{~m}^{3}$, foi destinado para o Estado do Rio de Janeiro, ficando o restante distribuído entre os outros Estados, com valores pouco expressivos, variando de $0,08 \%\left(31,49 \mathrm{~m}^{3}\right)$ para o Estado do Rio Grande do Sul; 0,11\% para o Estado de Roraima $\left(41,8 \mathrm{~m}^{3}\right) ; 0,13 \%$ para o Estado do Amazonas, com $47,94 \mathrm{~m}^{3} ; 0,4 \%$ foi destinado ao Estado do Paraná $\left(158,43 \mathrm{~m}^{3}\right) ; 0,55 \%$ para o Estado de Minas Gerais, com 207,5 $\mathrm{m}^{3} ; 1 \%$ $\left(373,78 \mathrm{~m}^{3}\right)$ para o Estado do Pará; até $1,6 \%$ $\left(601,62 \mathrm{~m}^{3}\right)$ para o Estado de São Paulo. O total de madeira serrada produzida no Estado do Rio de Janeiro foi de mais de $37000 \mathrm{~m}^{3}$, representando um valor de mais de 10 milhões de reais. A madeira serrada destinada ao Estado do Rio de Janeiro, com origem em municípios do Rio de Janeiro, no período de setembro de 2006 a dezembro de 2007, teve como maior fornecedor o município do Rio de Janeiro com um movimento de $14.295,68 \mathrm{~m}^{3}$, representando $38 \%$ de todo o volume registrado. Em seguida, com $5612,9 \mathrm{~m}^{3}$, aparece o município de Duque de Caxias, representando 15\% do volume total de madeira serrada originada nos municípios do Rio de Janeiro. Outros municípios - como Nova Friburgo com $2.885,66 \mathrm{~m}^{3}$, representando $8 \%$ do total; Campos dos Goytacazes com $1.687,74 \mathrm{~m}^{3}$, representando $5 \%$ do total; Petrópolis com 1.637,26 $\mathrm{m}^{3}$ e Itaguaí com $1.018,13 \mathrm{~m}^{3}$, representando $3 \%$ do total completam a lista daqueles com movimentação superior a $1.000 \mathrm{~m}^{3}$ no período mencionado. $\mathrm{O}$ restante do volume de $10.300 \mathrm{~m}^{3}$ está distribuído entre os 86 municípios que completam o Estado. Analisando a distribuição de madeira serrada originada no Estado do Rio de Janeiro, mas, excluindo o município do Rio de Janeiro, verifica-se uma grande variação nos volumes produzidos, variando de menos de $1 \mathrm{~m}^{3}$ no município de São João de Meriti a mais de $5.000 \mathrm{~m}^{3}$ no município de Duque de Caxias. Do volume total, somente 13 municípios tiveram movimentação superior a $500 \mathrm{~m}^{3}$ durante o período analisado, movimentando mais de $22.000 \mathrm{~m}^{3}$ de madeira serrada, alcançando mais de 13 milhões de reais. O restante dos municípios fornecedores com movimentação menor que $500 \mathrm{~m}^{3}$ responderam por mais de $4.200 \mathrm{~m}^{3}$ com um valor de quase 4 milhões de reais.

b) Origem no município do Rio de Janeiro - Na distribuição da madeira serrada originada no município do Rio de Janeiro, temos uma grande concentração na Região Metropolitana que responde por mais de $86 \%$ do volume total que sai do município do Rio de Janeiro, ultrapassando os $12.000 \mathrm{~m}^{3}$. O restante do volume produzido no município do Rio de Janeiro está distribuído entre as outras regiões: com 4,11\% para a região centro-sul; $3,4 \%$ da Costa Verde; 3,7\% para a região norte fluminense; de $2 \%$ para a região das baixadas; e $1,4 \%$ para a Região Serrana. A região noroeste fluminense é a única que não recebeu madeira serrada proveniente do município do Rio de Janeiro. A distribuição do volume de madeira serrada originado pelo município do Rio de Janeiro, com destino aos municípios do Estado, excetuando-se o próprio município no período do estudo, foi bastante variada. Dos 91 municípios, somente 36 receberam 
madeira proveniente do município do Rio de Janeiro. O município que mais recebeu madeira foi Comendador Levy Gasparian com 573,91 $\mathrm{m}^{3}$ e, mesmo assim, ficou na faixa dos $17 \%$ do volume total. O menor valor, $2,13 \mathrm{~m}^{3}$, foi registrado para o município de Nilópolis. Os 29 municípios com menos de $5 \%$ do volume total receberam em conjunto $875,94 \mathrm{~m}^{3}$. Os outros 7 municípios receberam um total de $2157 \mathrm{~m}^{3}$. Os 41 municípios fornecedores de madeira serrada realizaram mais de 450 movimentações do produto, entre eles, no período de setembro de 2006 a dezembro de 2007, excluindo a madeira movimentada dentro do próprio município. No ano de 2007, trinta e dois destes municípios forneceram madeira serrada para outros municípios, tendo o município de Duque de Caxias liderado, fornecendo o produto para 34 municípios. Em seguida, temos os municípios de Petrópolis, com fornecimento de madeira serrada para 32 municípios; Itaperuna, com o fornecimento para 25 municípios; Barra Mansa, com 21 fornecimentos; e Nova Iguaçu, atendendo a 20 municípios. Os municípios de Cabo Frio e Nova Friburgo forneceram madeira serrada para 15 municípios cada. O restante dos municípios teve atendimento abaixo de 10 municípios.

\subsubsection{Preço de madeira serrada}

Os preços da madeira serrada que ingressou no Estado, quase não tiveram variação expressiva, ficando o valor médio, no período de setembro de 2006 a dezembro de 2007, no patamar dos $\mathrm{R} \$ 348,33 / \mathrm{m}^{3}$. A exceção cabe ao município de Sumidouro, com mais de $100 \%$ em relação à média, com preço de R $\$ 707,14 / \mathrm{m}^{3}$; ao município de São Sebastião do Alto, que pagou, em média, R\$ 597,7/ $\mathrm{m}^{3}$; e ao município de Comendador Levy Gasparian, com preço médio de $\mathrm{R} \$ 594,33 / \mathrm{m}^{3}$, mostrando um acréscimo de cerca de $70 \%$; e ainda o município de Laje do Muriaé, que praticou preço médio de $\mathrm{R} \$ 557,66 / \mathrm{m}^{3}$, com uma elevação de cerca de $60 \%$ no preço médio da madeira serrada. Finalmente, fechando a lista daqueles municípios que fugiram à média, está o município de Valença, que teve preço médio de $\mathrm{R} \$ 532,7 / \mathrm{m}^{3}$, com uma elevação de $52 \%$. Em relação aos preços da madeira comercializada dentro do Estado, foi grande a variação dos valores praticados pelos municípios. Os valores variaram de $\mathrm{R} \$ 142,87 / \mathrm{m}^{3}$ registrado, para o município de Petrópolis, chegando até a $\mathrm{R} \$ 2.064,6 / \mathrm{m}^{3}$, no município de Armação dos Búzios. A média para todo o Estado ficou em R $\$ 892,41 / \mathrm{m}^{3}$. Somente 42 dos municípios do Estado produziram madeira serrada durante o período avaliado, totalizando mais de 26 milhões de $\mathrm{m}^{3}$, referente a um volume de $36.037,55 \mathrm{~m}^{3}$.

\section{DISCUSSÃO E CONCLUSÕES}

Analisando o mercado de produtos florestais no Estado do Rio de Janeiro é possível identificar, logo a princípio, que a produção de produtos florestais não madeireiros é pouquíssimo expressiva, estando reduzida ao Caju e a algumas fibras. Já em relação aos produtos florestais, é possível identificar uma movimentação de produtos como lenha, carvão, madeira em toras e madeira serrada. Este mercado engloba tanto os produtos do reflorestamento como aqueles provenientes de áreas com cobertura florestal nativa.

A produção de produtos florestais no Estado, tendo como base as informações da pesquisa Produção da Extração Vegetal e Silvicultura, do IBGE, mostra que a produção de lenha e carvão de mata nativa, ainda existe. A produção de carvão, por exemplo, apesar de mostrar um declínio no ano de 2003, voltou a apresentar uma elevação de mais de $80 \%$ em 2006, o que causa estranheza se considerarmos a conhecida redução das áreas de mata nativa no Estado. Fato similar aconteceu com a produção de lenha, que, apesar de um declínio até 2005, mostrou uma elevação de mais de 50\% em 2006, mostrando que existe uma demanda por este tipo de produto, apesar das restrições legais. A produção de madeira em toras mostra um declínio mais expressivo do ano de 2002 para 2005, mas apresenta uma elevação de mais de $8 \%$ para o ano de 2006. Estes dados, considerados como informação oficial, atestam que, apesar das restrições legais e da pressão da sociedade visando à conservação e preservação dos recursos florestais, ainda existe no Estado do Rio de Janeiro, atividades de extração de produtos florestais nos remanescentes florestais nativos. 
No tocante aos reflorestamentos, ainda de acordo com a pesquisa Produção da Extração Vegetal e Silvicultura, do IBGE, existe uma demanda expressiva por produtos florestais provenientes de reflorestamentos. A produção de carvão vegetal que tinha um valor de 802 t em 2002 alcançou a marca de mais de 5.000 t nos anos de 2005 e 2006, mostrando uma elevação de mais de $600 \%$. A produção de lenha teve um pequeno declínio do ano de 2002 a 2003, mas fechou o ano de 2006 com um acréscimo de cerca de mais de $40 \%$ para o ano de 2002. A produção de madeira para a produção de papel e celulose mostra uma expressiva elevação no ano de 2006, alcançando mais de $104.000 \mathrm{~m}^{3}$ produzidos, contrastando com a produção de 2004 que não ultrapassou os $12.000 \mathrm{~m}^{3}$. A produção de madeira de reflorestamentos destinada ao grupo "outras finalidades" apresentou um crescimento constante a partir do ano de 2004, alcançando valores da ordem dos $80.000 \mathrm{~m}^{3}$ produzidos.

A movimentação de produtos florestais no Estado do Rio de Janeiro foi analisada de acordo com as informações do DOF, IBAMA, englobando a madeira na forma de lenha, carvão ou madeira serrada, identificando origem e destino destes produtos dentro e fora do Estado.

No tocante à movimentação de lenha no ano de 2006, de setembro a dezembro, e no ano de 2007, não foi registrado nenhum movimento de cargas de lenha com destino ao Estado do Rio de Janeiro ou originadas em municípios do Rio de Janeiro. Este dado contrasta com aquele fornecido pelo IBGE que registra uma produção de mais de $53.000 \mathrm{~m}^{3}$ no ano de 2006 .

Este contraste também aparece na comparação com informações referentes ao carvão vegetal. Apesar do registro do IBGE de uma produção para 2006 de 124 t, não há registro, no IBAMA, da movimentação deste subproduto naquele ano. Entretanto foi registrado no período analisado, pelo IBAMA, de uma movimentação de mais de $160.000 \mathrm{~m}^{3}$ de carvão vegetal, oriundos de matas nativas dos Estados do Mato Grosso do Sul e Paraná.

Em relação à movimentação de madeira em toras, com origem no próprio Estado, não houve registro desta atividade no ano de 2006 e em 2007, apenas o município de Duque de Caxias aparece como fornecedor. Estes dados de novo contrastam com o IBGE, que acusa uma produção de mais de $1000 \mathrm{~m}^{3}$ de madeira em toras somente no ano de 2006. No tocante à madeira em toras originada em outros Estados, conforme o IBAMA, houve registro de $479 \mathrm{~m}^{3}$ que entraram no Estado, de setembro de 2006 a dezembro de 2007. Todo este volume de madeira em toras, vindo de fora do Estado, foi proveniente do Estado do Piauí. Este dado sobre esta movimentação chama a atenção, pois os municípios fornecedores no Estado do Piauí, como São Raimundo Nonato, Várzea Branca e Santa Luz estão na região da Serra do Capivari que enfrenta problemas com a exploração da cobertura florestal remanescente. Também causa espécie o volume de madeira em toras originado no município de Duque de Caxias, que não apresenta registro de recebimento de madeira em toras, dificultando saber de que mata nativa ela estaria sendo explorada.

A madeira serrada, aqui englobando todos aqueles produtos e subprodutos listados anteriormente, que entrou no Estado do Rio de Janeiro, foi distribuída entre os municípios fluminenses, mostrando uma grande demanda por estes produtos, variando conforme o desenvolvimento de cada um dos municípios.

O ingresso de madeira serrada no Estado, conforme mostrado anteriormente na região norte do País, teve o maior peso no volume importado. $\mathrm{Na}$ distribuição deste material, fica claro que as regiões mais próximas da capital do Estado, como a metropolitana, receberam o maior volume de madeira serrada. A região das baixadas litorâneas recebeu o segundo maior volume, o que pode ser explicado pelo grande número de empreendimentos na área da construção civil. No tocante ao recebimento de madeira pelos municípios, mais uma vez o município do Rio de Janeiro aparece como o de maior volume recebido. Em relação ao restante do Estado, pode-se dizer que houve uma pulverização entre os 88 municípios do restante do volume de madeira serrada que ingressou no Estado. Esta variação é sentida quando se observa a amplitude dos volumes recebidos que vão de $5 \mathrm{~m}^{3}$ recebidos pelo município de São José de Ubá até $3.500 \mathrm{~m}^{3}$ recebidos pelo município de Itaboraí.

Em relação à madeira serrada com origem no próprio Estado, está o registro do envio de madeira 
serrada para a região norte fluminense, sul e sudeste. $\mathrm{O}$ volume de madeira serrada para estas regiões não chegou a $4 \%$ do total de madeira serrada originada no Estado. O município do Rio de Janeiro desponta como o grande fornecedor de madeira serrada internamente, distribuindo para os outros municípios e para ele próprio.

$\mathrm{Na}$ observação da distribuição da madeira serrada com origem em municípios do Rio de Janeiro, é possível identificar alguns municípios que funcionam como polos de dispersão da madeira produzida. Municípios como Duque de Caxias, Nova Friburgo, Campos dos Goytacazes, Petrópolis e Itaguaí aparecem como os maiores distribuidores de madeira serrada, quando se exclui o município do Rio de Janeiro.

$\mathrm{Na}$ distribuição de madeira serrada proveniente do município do Rio de Janeiro, somente a região noroeste fluminense não recebeu nenhum produto. $\mathrm{O}$ restante das regiões teve recebimentos variando de $27,30 \mathrm{~m}^{3}$ na região do Médio Paraíba até mais de $500 \mathrm{~m}^{3}$ recebidos pela região centro-sul fluminense.

$\mathrm{Na}$ distribuição da madeira serrada com origem em municípios do Rio de Janeiro, somente 32 municípios tiveram movimentação entre outros municípios, criando uma grande rede de distribuição de madeira serrada.

Em relação aos preços praticados, não houve variação expressiva em relação à madeira serrada que entrou no Estado. Conforme já foi dito anteriormente, somente o município de Sumidouro apresentou uma variação de mais de $100 \%$ no preço da madeira comercializada.

No tocante aos preços de madeira serrada comercializada com origem no Estado do Rio de Janeiro, existe uma grande variação com valores alcançando mais de 2.000 reais por metro cúbico. Isto pode ser explicado pela agregação de valor ao produto, por condições de mercado ou mesmo pelo valor da madeira, que varia conforme a espécie florestal.

O Estado do Rio de Janeiro tem uma demanda por produtos florestais bastante expressiva, desde lenha e carvão vegetal até madeira serrada, passando por madeira para papel e celulose e também para o grupo "outras finalidades". Este fato é corroborado quando se verifica o volume total ingressado no Estado. Apesar do consumo, ainda existente, da madeira retirada das matas nativas do Estado, é notável que a madeira proveniente dos reflorestamentos esteja ocupando lugar de destaque, impulsionado pela demanda por certo tipo de produtos. Este é o caso da madeira destinada a "outras finalidades" que engloba aquela madeira utilizada na indústria da construção civil, mais barata e de menor qualidade que vem sendo usada para escoramento e outras utilizações menos nobres.

\section{STATUS DA SUBMISSÃO}

Recebido: 04/11/2008

\section{AUTOR(ES) PARA CORRESPONDÊNCIA}

\section{Wilson Ferreira de Mendonça Filho}

Instituto de Florestas - IF,

Universidade Federal Rural do Rio de Janeiro,

BR 465, Km 07, CEP 23890-000,

Seropédica, RJ, Brasil

e-mail: mendonca@ufrrj.br;

wilsonmendonca@uol.com.br

\section{REFERÊNCIAS}

Instituto Brasileiro de Geografia e Estatística - IBGE. Produção da Extração Vegetal e Silvicultura. Rio de Janeiro: IBGE; 2003.

Instituto Brasileiro do Meio Ambiente - IBAMA. Produção da Extração Vegetal e Silvicultura. Rio de Janeiro: IBGE; 2004

Instituto Brasileiro do Meio Ambiente - IBAMA. Produção da Extração Vegetal e Silvicultura. Rio de Janeiro: IBGE; 2005

Instituto Brasileiro do Meio Ambiente - IBAMA. Produção da Extração Vegetal e Silvicultura. Rio de Janeiro: IBGE; 2007.

Instituto Brasileiro do Meio Ambiente - IBAMA. Relatório de movimentações no sistema DOF referentes ao Estado do Rio de Janeiro do ano de 2006. Brasília: IBGE; 2006. $8 \mathrm{p}$.

Instituto Brasileiro do Meio Ambiente - IBAMA. Relatório de movimentações no sistema DOF referentes ao Estado do Rio de Janeiro do ano de 2007. Brasília: IBGE; 2006. $8 \mathrm{p}$. 